\title{
Underground environment parameter prediction in a deep mine
}

\author{
WS Lyu University of Science and Technology Beijing, China \\ SJ Cai University of Science and Technology Beijing, China \\ P Yang Beijing Union University, China \\ YL Zhang University of Science and Technology Beijing, China
}

\begin{abstract}
To manage heat load problems in deep mining, a research program for measuring and predicting the underground environment parameters was carried out in Jiudian gold mine. The deposit is buried from 150 to $-950 \mathrm{~m}$ underground. The development drifts reach the $-710 \mathrm{~m}$ Level and the mine's main production levels are at -510 and $-550 \mathrm{~m}$. The mine encountered several hot springs, though blocked, the springs still affect the underground environment. Some environment parameters were measured at three mining levels in summer and winter, including the temperature and moisture of air flow, and the temperature of the rock face and of the internal rock mass. Based on the energy conservation law and the mass conservation law, an environment parameter prediction model was built, and the corresponding computer program was developed using $\mathrm{C}++_{+}$ language. Comparison of predicted and measured data proved the reliability of the environment parameter prediction model.
\end{abstract}

Keywords: deep mining, environment parameter, prediction model

\section{Introduction}

Generally, the normal exposed skin temperature of a human being is around $27^{\circ} \mathrm{C}$ ( $\mathrm{Li}$ et al. 2002), and the work environment temperature standard is $28^{\circ} \mathrm{C}$ of dry bulb temperature, according to the 'Safety Regulations for Metal and Non-metal Mines' (Standardization Administration of the People's Republic of China 2006). However, in deep underground mines a high hygrothermal environment is formed due to the high temperature and moisture. In this environment, the heat adjusting function of the human body would be reduced greatly, and may lead to heat stroke (Peng 2014; Lu et al. 2007). Statistical data has shown that the working productivity of miners reduces by $7 \%$ for every $1^{\circ} \mathrm{C}$ increase than the required safety standard at the working face of the underground mine (Su et al. 2008; Tan 2007). Hence, effective air flow treatment is important for the safety and production of any underground mine, especially in a deep mine (Liu et al. 2008; Brake 2002).

The Jiudian gold mine is located in Pingdu, Shandong province, China. The orebodies are buried from 150 to $-950 \mathrm{~m}$ underground. The $1 \#$ vein is the main orebody and has a discontinuous lens shape, with strike a direction of northeast $20-55^{\circ}$, dipping angle of $70-80^{\circ}$, and is $0.5-4.0 \mathrm{~m}$ thick, and $4,000-5,000 \mathrm{~m}$ long. Presently, the development drifts have reached the $-710 \mathrm{~m}$ Level, and production occurs mainly at the -510 and $-550 \mathrm{~m}$ levels (Figure 1), (Zhang 2012). A number of hot springs exist at several levels. Warm water gushed out of these springs at a temperature of up to $73^{\circ} \mathrm{C}$ (Zheng et al. 2009). Down to the $-510 \mathrm{~m}$ Level the temperature of the hot springs remains stable. Although some measures were taken to block the hot springs for safety, they still affect the temperature of rocks to some extent. The high temperature impacted the mine ventilation (Brake 2002; Chow 1995). To understand the underground environment, a research programme has been carried out, including climatic parameter measurement and climatic prediction at depth. 


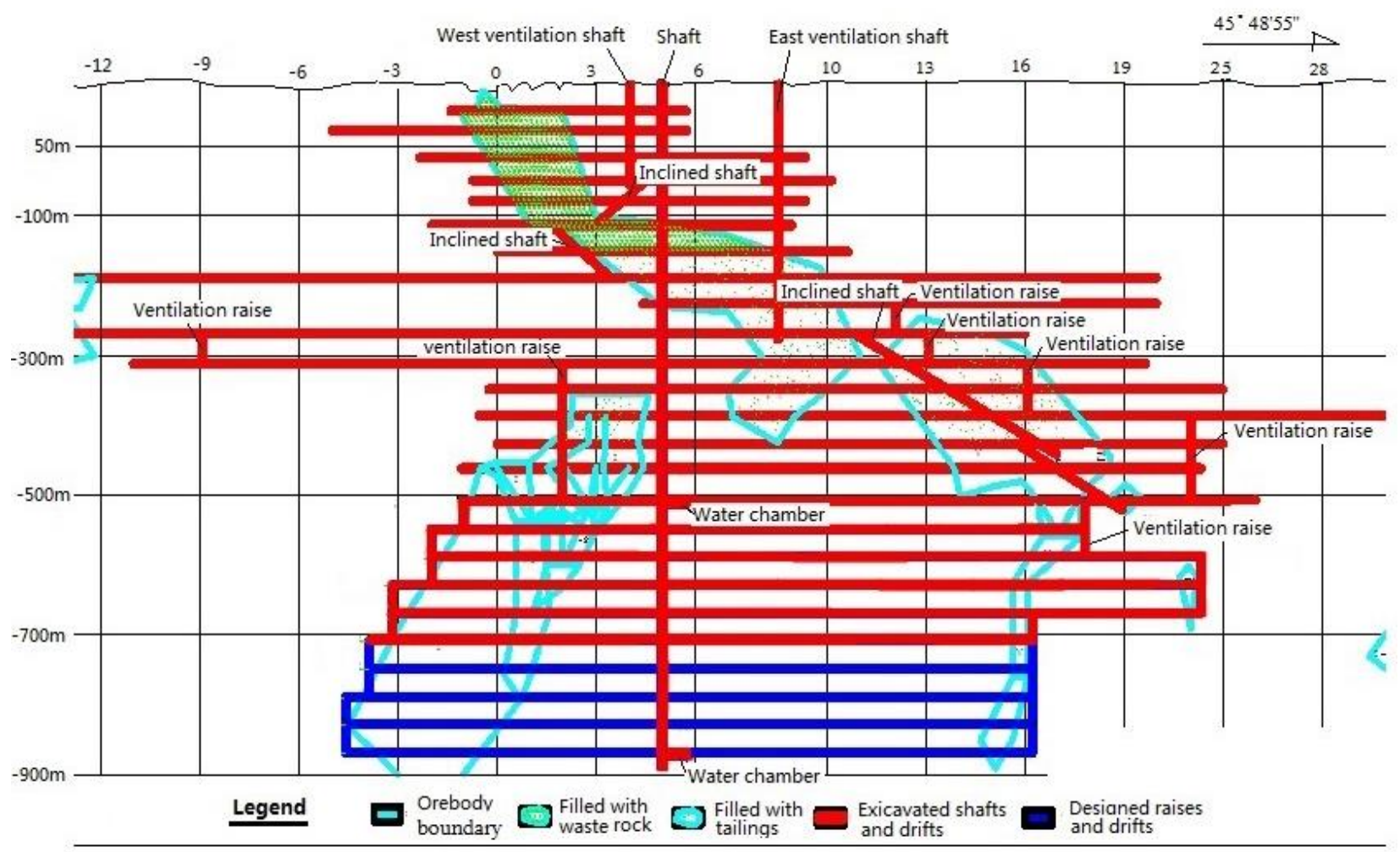

Figure 1 Longitudinal profile of the Jiudian gold mine

\section{Measurement of environment parameters}

To obtain a thorough knowledge of the underground environment, measurements were taken in summer and winter (Zhang 2012).

\subsection{Measurement of air flow parameters}

A portable CZC5 multi-parameter measuring gauge was used in the field, (Figure 2(a)). With this instrument, the air pressure, temperature, moisture and airflow speed can be measured and stored for subsequent analysis. The measurements were taken mainly at three mine levels. Some measured data are listed in Table 1. The data shown that, at some times, the highest temperature is $30.8^{\circ} \mathrm{C}$, which is higher than the national standard.

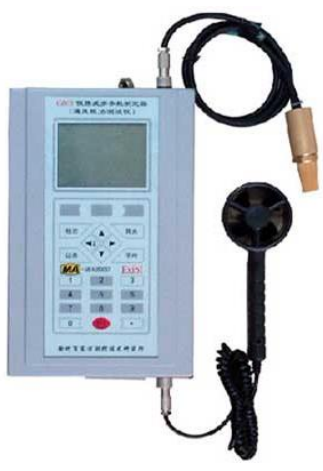

(a)

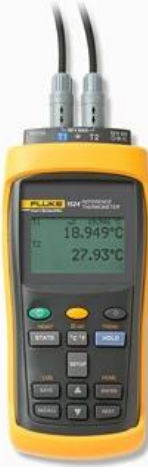

(b)

Figure 2 Instruments used in underground environment investigation: (a) CZC5 portable multi-parameter measuring gauge; and, (b) heat-sensing NTC thermal resistance thermo-scope 
Table 1 Environmental parameters of the Jiudian Mine air flow

\begin{tabular}{lllll}
\hline Measuring site & $\begin{array}{l}\text { Summer } \\
\text { Temperature } \\
\left(\mathbf{t},{ }^{\circ} \mathbf{C}\right)\end{array}$ & $\begin{array}{l}\text { Moisture } \\
(\boldsymbol{\varphi}, \%)\end{array}$ & $\begin{array}{l}\text { Winter } \\
\text { Temperature } \\
\left(\mathbf{t},{ }^{\circ} \mathbf{C}\right)\end{array}$ & $\begin{array}{l}\text { Moisture } \\
(\boldsymbol{\varphi}, \%)\end{array}$ \\
\hline $\begin{array}{l}\text { At -470 m Level } \\
\begin{array}{l}\text { 1) Bottom of filling } \\
\text { raise }\end{array}\end{array}$ & 24.2 & 97.1 & 20.2 & 96.5 \\
\hline $\begin{array}{l}\text { 2) Level drift } \\
\text { 3) Stope 1 }\end{array}$ & 24.0 & 98.4 & 19.9 & 98.1 \\
\hline 4) Stope 2 & 28.2 & 99.2 & 24.8 & 98.6 \\
\hline At -510 m Level & 28.8 & 99.5 & 25.2 & 98.5 \\
\hline $\begin{array}{l}\text { 1) Bottom of filling } \\
\text { raise }\end{array}$ & 28.2 & 97.8 & 25.1 & 97.2 \\
\hline 2) Level drift & 28.1 & 98.2 & 24.9 & 98.1 \\
\hline 3) Stope 3 & 29.6 & 99.6 & 26.3 & 99.1 \\
\hline 4) Stope 4 & 29.5 & 99.6 & 26.5 & 99.3 \\
\hline At -550 m Level & & & & 99.5 \\
\hline 1) Bottom of filling & 29.5 & 98.0 & 25.8 & 97.6 \\
\hline $\begin{array}{l}\text { raise } \\
\text { 2) Level drift }\end{array}$ & 29.8 & 98.8 & 25.6 & 98.2 \\
\hline 3) Stope 5 & 30.8 & 99.7 & 27.8 & 99.3 \\
\hline 4) Stope 6 & 30.8 & 99.8 & 27.2 & 99.5 \\
\hline & & & & \\
\hline
\end{tabular}

\subsection{Measurement of rock temperature}

As the mining depth increases, the geothermal effect will become more obvious in the mining openings (Hu 1994; Chen 2004). The main factors influencing the drift rock surface temperature include: drift geometry, ventilation time, temperature difference between air flow and rock, and rock thermo-physical parameters.

The rock thermo-physical parameters of the Jiudian gold mine are listed in Table 2.

Table 2 Rock thermo-physical parameters in Jiudian Mine

\begin{tabular}{lllll}
\hline Rock type & $\begin{array}{l}\text { Thermal conductivity } \\
\text { coefficient } \\
\left(\mathbf{W} \cdot \mathbf{m}^{-1} \cdot{ }^{\circ} \mathbf{C}-1\right)\end{array}$ & $\begin{array}{l}\text { Specific heat } \\
\left(\mathbf{J} \cdot \mathbf{k g}^{-1} \cdot{ }^{\circ} \mathbf{C}-1\right)\end{array}$ & $\begin{array}{l}\text { Rock } \\
\text { density } \\
\left(\mathbf{k g} \cdot \mathbf{m}^{-3}\right)\end{array}$ & $\begin{array}{l}\text { Heat } \\
\text { diffusivity } \\
\left(\mathbf{1 0}^{-6} \mathbf{~ m}^{\mathbf{2}} \cdot \mathbf{s}^{-1}\right)\end{array}$ \\
\hline $\begin{array}{l}\text { Medium-granular } \\
\text { sandstone }\end{array}$ & 2.771 & 0.899 & 2,630 & 1.171 \\
$\begin{array}{l}\text { Limestone } \\
\begin{array}{l}\text { Small-granular } \\
\text { sandstone }\end{array}\end{array}$ & 2.316 & 0.907 & 2,879 & 0.953 \\
\hline \begin{tabular}{l} 
Shale \\
\hline
\end{tabular} & 2.099 & 0.982 & 2,575 & 0.828 \\
\hline
\end{tabular}


To measure the original rock temperature underground, fresh working faces of a drift and stope were selected in order to minimise the airflow influence. The shallow hole (hole depth of 2-3 $\mathrm{m}$ ) measuring method was used in the investigation (Chen 1993; Liu et al. 2005).

The relationship of hole depth for virgin rock temperature measurement and rock face exposure time can be illustrated as follows. Suppose the rock face is dry, homogeneous and semi-infinite, and let the direction perpendicular to rock face be the $x$ axis. If the rock face exposure time is $\tau$, then the temperature at any point on the $x$ axis would be $t(x, \tau)$. Based on the heat conduction principle, and with a constant temperature air flow, the relationship would be as defined by Equation (1) (Chow 1995):

$$
\frac{\partial t}{\partial \tau}=\alpha \frac{\partial^{2} t}{\partial x^{2}}
$$

Where $\tau=0, t=t_{a}$, which is regarded as the original rock temperature; where $\tau>0$ and $x=0, t=t_{b}$, which means the rock temperature equals the air flow temperature:

$$
\begin{aligned}
& \mathrm{x}=\text { depth of heat measuring hole, } \mathrm{m} . \\
& \mathrm{t}_{\mathrm{a}}=\text { original rock temperature, }{ }^{\circ} \mathrm{C} . \\
& \mathrm{t}_{\mathrm{b}}=\text { air flow temperature, }{ }^{\circ} \mathrm{C} . \\
& \alpha=\text { rock heat diffusivity, } \mathrm{m}^{2} / \mathrm{s} .
\end{aligned}
$$

Solving Equation (1):

$$
\frac{t-t_{a}}{t_{b}-t_{a}}=\operatorname{erfc}\left(\frac{x}{2 \sqrt{\alpha \cdot \tau}}\right)
$$

where:

$$
\operatorname{erfc}\left(\frac{x}{2 \sqrt{\alpha \cdot \tau}}\right) \text { is the Gauss error function. }
$$

Let $\frac{t-t_{a}}{t_{b}-t_{a}}=0.999$, then $\operatorname{erfc}\left(\frac{x}{2 \sqrt{\alpha \cdot \tau}}\right)=0.999$, from the Gauss table we know $\frac{x}{2 \sqrt{\alpha \cdot \tau}}=2.4$, and finally, the relationship of rock face exposure time and heat measuring hole depth is given by Equation (3):

$$
x=4.8 \sqrt{\alpha \cdot \tau}
$$

For example, the heat diffusivity of the medium-granular sandstone in Table 2 is $\alpha=1.171 \times 10^{-6} \mathrm{~m}^{2} / \mathrm{s}$, with Equation (3), when $\tau=6,12$ and $24 \mathrm{hrs}$, then the hole depth for heat measuring will be $0.76,1.07$ and $1.52 \mathrm{~m}$, respectively.

The instrument used in the field to measure rock face temperature was the heat-sensing NTC thermal resistance thermo-scope (Figure 2(b)).

For precise temperature measurement inside a rock body, some modifications of the measuring process were undertaken in situ. As shown in Figure 3, when the measuring hole was finished thermistors were stuck on the end of an elastic emulsion pipe, and then the pipe was installed inside the hole. The measuring hole was sealed with a water-stem, and a gas tube was left outside the hole. When pumping air into the emulsion pipe through the gas tube, the pipe would expand and then the thermistors could contact the rock wall tightly. After the tube was pressurised, measurement started. Data were recorded once an hour for $24 \mathrm{hrs}$. Some measured results are listed in Table 3. 


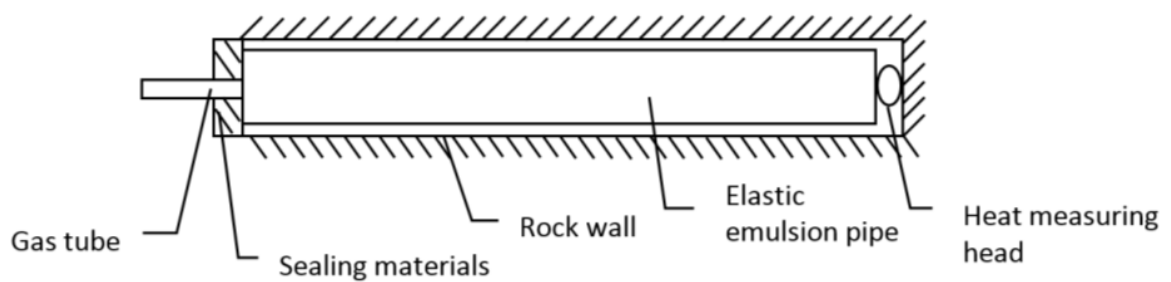

Figure 3 Rock temperature measurement sketch

Table 3 Measured rock temperature in the Jiudian Mine

\begin{tabular}{|c|c|c|c|c|c|}
\hline Measuring site & $\begin{array}{l}\text { Measuring } \\
\text { hours } \\
\text { (hrs) }\end{array}$ & $\begin{array}{l}\text { Hole } \\
\text { depth } \\
\text { (m) }\end{array}$ & $\begin{array}{l}\text { Drift } \\
\text { temperature } \\
\left({ }^{\circ} \mathrm{C}\right)\end{array}$ & $\begin{array}{l}\text { Rock face } \\
\text { temperature } \\
\left({ }^{\circ} \mathrm{C}\right)\end{array}$ & $\begin{array}{l}\text { Rock inside } \\
\text { temperature } \\
\left({ }^{\circ} \mathrm{C}\right)\end{array}$ \\
\hline \multicolumn{6}{|l|}{ At -470 m Level } \\
\hline $\begin{array}{l}\text { 1) Bottom of filling } \\
\text { raise }\end{array}$ & 24 & 2 & 23.1 & 23.1 & 28.5 \\
\hline 2) Level drift & 24 & 2 & 23.3 & 23.4 & 28.6 \\
\hline 3) Stope 1 & 24 & 2 & 27.6 & 27.6 & 28.6 \\
\hline 4) Stope 2 & 24 & 2 & 27.6 & 27.7 & 28.7 \\
\hline Average & - & - & - & - & 28.6 \\
\hline \multicolumn{6}{|l|}{ At $-510 \mathrm{~m}$ Level } \\
\hline $\begin{array}{l}\text { 1) Bottom of filling } \\
\text { raise }\end{array}$ & 24 & 2 & 27.8 & 27.9 & 31.9 \\
\hline 2) Level drift & 24 & 2 & 27.9 & 27.9 & 32.5 \\
\hline 3) Stope 3 & 24 & 2 & 28.6 & 28.7 & 32.7 \\
\hline 4) Stope 4 & 24 & 2 & 28.5 & 28.8 & 32.8 \\
\hline Average & - & - & - & - & 32.5 \\
\hline \multicolumn{6}{|l|}{ At -550 m Level } \\
\hline $\begin{array}{l}\text { 1) Bottom of filling } \\
\text { raise }\end{array}$ & 24 & 2 & 28.1 & 28.3 & 35.3 \\
\hline 2) Level drift & 24 & 2 & 28.5 & 28.7 & 35.7 \\
\hline 3) Stope 5 & 24 & 2 & 29.2 & 29.2 & 35.3 \\
\hline 4) Stope 6 & 24 & 2 & 29.1 & 29.2 & 35.2 \\
\hline Average & - & - & - & - & 35.4 \\
\hline
\end{tabular}

The calculated thermal gradient over the $80 \mathrm{~m}$ vertical interval between the -470 and -550 Level is $8.5^{\circ} \mathrm{C} / 100 \mathrm{~m}$. This is much higher than the ordinary gradient, due to the effect of the underground hot springs.

\subsection{Hygrothermal exchange calculation}

Heat exchanges from the wall and hot water to airflow in the drift, mainly are convective heat transfer and convective mass transfer (Zuo 2009). For the dry walls, the main heat is sensible heat transferring $q_{s}$; for wet walls and for the hot ditch water, there exist two forms of heat transfer: the latent heat transferring $q_{\text {I }}$ and sensible heat transferring $q_{s}$. 


\subsubsection{Sensible heat calculation}

Sensible heat can be calculated according to the convective heat transferring law.

where:

$$
Q_{s}=a \cdot\left(T_{w}-T_{f}\right) \cdot A
$$

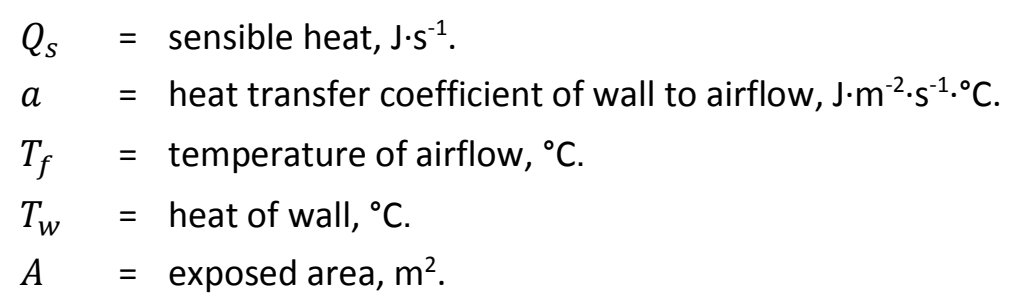

\subsubsection{Latent heat calculation}

Latent heat calculation is needed when the heat exchanges from the wet wall and hot water to air flow. As the air flow is turbulent, the moisture exchange is convectional moisture exchange.

Suppose the contact surface of wet objects with air flow is $d F$, the moisture exchange is:

$$
d w=\frac{a_{D} \cdot\left(e_{S}-e\right) \cdot d F}{R_{S} \cdot T_{S}}
$$

where:

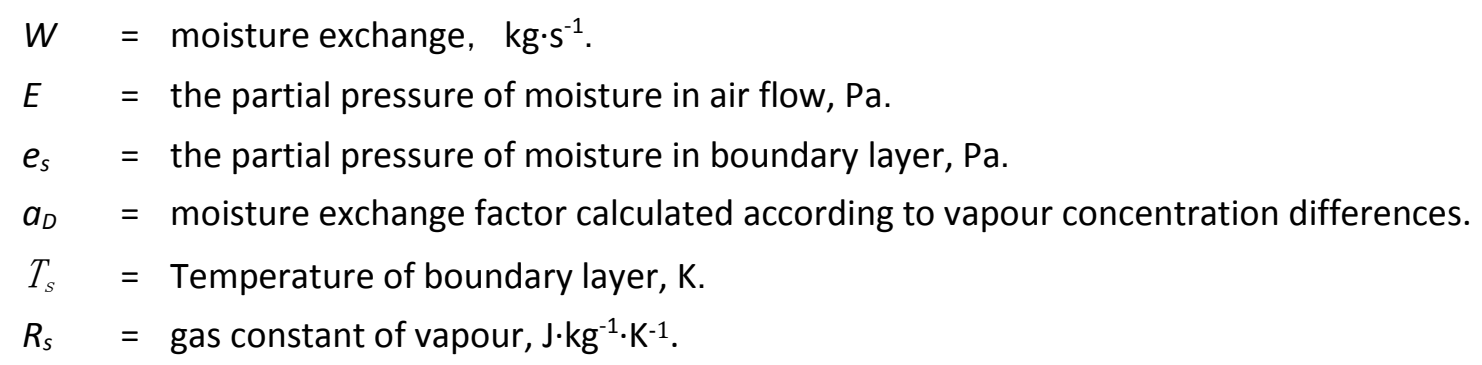

In general research, the Prandtl number $P_{r}$ is usually substituted by Schmidt number $S_{c}$, and Nusselt number $N_{u}$ is usually substituted by Sherwood number $S_{h}$ in $a_{D}$ calculation. In the calculation, the Reno number $R_{e}$ should keep constant.

When Prandtl number $P_{r}$ equals to Schmidt $S_{c}$, there exist one special relationship between convection heat exchange and convection mass exchange:

$$
\frac{S_{c}}{P_{\mathrm{r}}}=\frac{a}{\Delta}=1
$$

where:

$$
\begin{aligned}
& a=\text { thermal diffusivity, } \mathrm{m}^{2} \cdot \mathrm{s}^{-1} . \\
& \Delta=\text { diffusion coefficient, } \mathrm{m}^{2} \cdot \mathrm{s}^{-1} .
\end{aligned}
$$

Here, $\frac{a}{\Delta}=L_{e}, L_{e}$ is usually called the Lewis number. In moisture exchange, $S_{h}=f\left(R_{e}, S_{c}\right)$, and in heat exchange, $\mathrm{N}_{u}=f\left(R_{e}, P_{r}\right)$. In certain air flow, when $R_{e}$ keeps constant, that means $P_{r}=S_{c}$ and $L_{\mathrm{e}}=1$, as $S_{h}=N_{u}$, thus we got:

$$
\frac{a_{D}}{\Delta}=\frac{a \cdot l}{\lambda}
$$

where:

$l \quad=$ length, $\mathrm{m}$.

$\lambda=$ thermal conductivity, $\mathrm{J} \cdot \mathrm{m}^{-1} \cdot \mathrm{s}^{-1} \cdot{ }^{\circ} \mathrm{C}$. 
As $\Delta=a$, and $a=\frac{\lambda}{C_{p} \cdot \rho}\left(C_{p}\right.$ specific heat at constant pressure, $\rho=$ density of fluid $)$, we have:

$$
a_{D}=\frac{\lambda}{C_{p} \cdot \rho} \cdot \frac{a}{\lambda}=\frac{a}{C_{p} \cdot \rho}
$$

and Equation (8) is the Lewis equation. It can be seen that this equation is applicable only when $\Delta=a$. According to partial pressure of vapour calculation function, we have:

$$
e=e_{s}-A \cdot p \cdot\left(t-t_{s}\right)
$$

where:

$p \quad=$ pressure of airflow, $\mathrm{Pa}$.

$A=$ modified coefficient of airflow speed.

$A=\frac{a}{\gamma \cdot \beta \cdot 101325}=\frac{C_{p} \cdot \rho \cdot R_{s} \cdot T_{s}}{\gamma \cdot 101325}$ here, $\gamma=$ heat of vaporisation of water, $\mathrm{J} \cdot \mathrm{kg}^{-1}$.

Substitute Equation (8) and (9) into (4), the function of evaporation of wall can be obtained:

$$
W_{\max }=\frac{a}{\gamma} \cdot \frac{P}{101325} \cdot\left(t-t_{s}\right) \cdot d F
$$

As $d F=U d l$, so Equation (10) can be transformed into:

$$
W_{\max }=\frac{a}{\gamma} \cdot \frac{P}{101325}\left(t-t_{s}\right) \cdot U \cdot d l
$$

and because $Q=W \cdot \gamma$, so the latent heat exchange caused by moisture exchange is:

$$
Q_{q \max }=1.9738 \times 10^{-5} a \cdot P \cdot U \cdot d l
$$

As there exists great damp differences between different patches of surface, in the evaporation calculation, a multiple humidity coefficient $f$, the ratio of real amount of evaporation to its maximum evaporation capacity of each tunnel section, should be introduced.

\section{Environment parameter prediction model}

For environmental treatment of a deep mine, it is important to predict the environment parameters of intake air to working areas underground (Zuo 2009; Lowndes et al. 2005).

\subsection{Temperature balance equation}

Based on energy conservation law, the air flow temperature balance equation is demonstrated as:

$$
m_{a} \cdot C_{p} \cdot d t_{v}=\alpha \cdot\left(t_{w}-t_{v}\right) \cdot P \cdot d L
$$

Integrating Equation (13), the temperature balance equation is:

$$
t_{v}{ }^{i}=t_{w}-\left(t_{w}-t_{v}{ }^{i-1}\right) \exp \frac{-a \cdot P \cdot \Delta L}{m_{a} \cdot C_{p}}
$$

where:

$$
\begin{aligned}
& \Delta L=\text { drift length, (m). } \\
& t_{v}^{j-1}=\text { air flow temperature of drift entry, }{ }^{\circ} \mathrm{C} . \\
& t_{v}^{i}=\text { air flow temperature of drift exit, }{ }^{\circ} \mathrm{C} .
\end{aligned}
$$




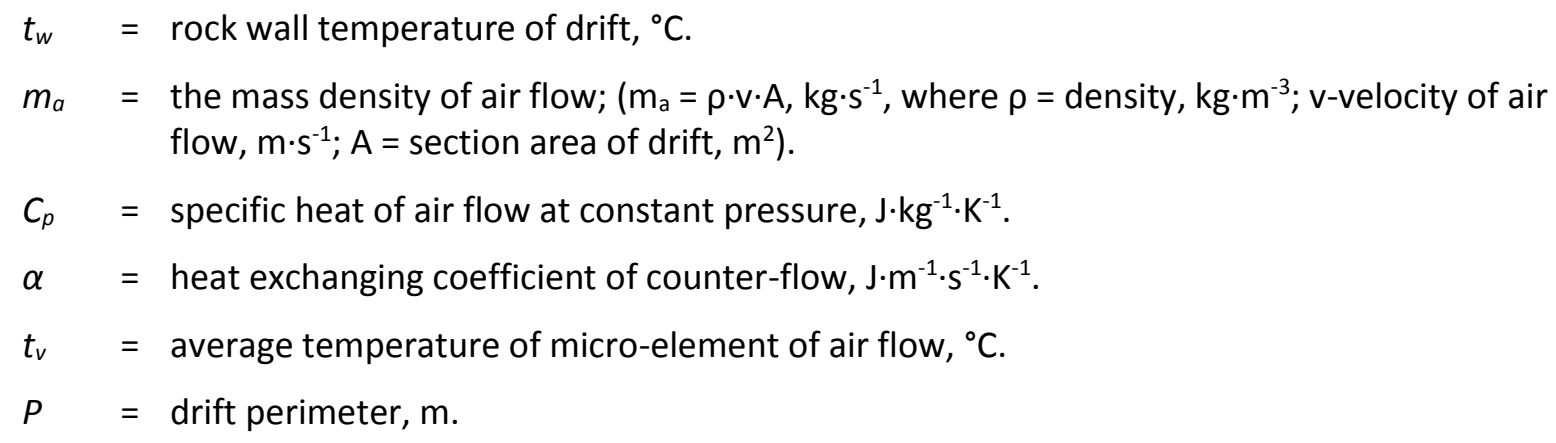

\subsection{Moisture balance equation}

Based on the mass conservation law, suppose $d(d)$ as the moisture change of each micro unit, the moisture balance equation can be written as:

$$
m_{a} \cdot \mathrm{d}(d)=f \cdot \beta_{p} \cdot\left(p_{w}-p_{v}\right) \cdot P \cdot d L=f \cdot \beta_{d} \cdot\left(d_{w}-d_{v}\right) \cdot P \cdot d L
$$

Integrating Equation (15), the temperature balance equation is:

$$
d_{v}{ }^{i}=d_{w}-\left(d_{w}-d_{v}^{i-1}\right) \exp \frac{-f \cdot \beta_{d} \cdot P \cdot \Delta L}{m_{a}}
$$

where:

$$
\begin{aligned}
& d_{v}=\text { average moisture of micro-element of air flow, } \mathrm{g} \cdot \mathrm{kg}^{-1} . \\
& f \quad=\text { air flow moisture covering rate of drift. } \\
& d \quad=\text { moisture in each micro unit, } \mathrm{g} \cdot \mathrm{kg}^{-1} . \\
& P_{\mathrm{w}}=\text { pressure of saturated water vapour, Pa. } \\
& B_{p}=\text { moisture exchanging coefficient calculated on pressure, } \mathrm{kg} \cdot \mathrm{m}^{-2} \cdot \mathrm{s}^{-1} \cdot \mathrm{Pa}^{-1} . \\
& d_{w}=\text { saturated moisture of wet drift wall boundary at temperature } \mathrm{t}_{\mathrm{ww}}, \mathrm{g} \cdot \mathrm{kg}^{-1} \cdot \\
& P_{\mathrm{v}}=\text { average pressure of micro-element of water-vapour, Pa. } \\
& b_{d}=\text { moisture exchanging coefficient calculated on moisture content, } \mathrm{kg} \cdot \mathrm{m}^{-2} \cdot \mathrm{s}^{-1} \cdot \mathrm{Pa}^{-1}
\end{aligned}
$$

\subsection{Solving the wall temperature}

The temperature and moisture of air flow is mostly determined by the drift wall conditions. If the country rock is homogeneous and the drift section is circular, and ignoring the temperature gradient of air flow in the axis direction, then under a wet wall condition, the mathematical model of drift wall temperature can be based on the energy conservation law:

$$
q=\left.\lambda \cdot \frac{\partial t(r, \tau)}{\partial r}\right|_{r=r_{0}}=a \cdot\left[t\left(r_{0}, \tau\right)-t_{v}\right]+r_{w} \cdot \beta_{d} \cdot\left(d_{w}-d_{v}\right)
$$

where:

$$
\begin{aligned}
& q \quad=\text { heat flux, } \mathrm{W} \cdot \mathrm{m}^{-2} ; \text { a-heat conductivity of rock mass, } \mathrm{W} \cdot \mathrm{m}^{-1} \cdot{ }^{\circ} \mathrm{C}^{-1} . \\
& r_{0} \quad=\text { equivalent radius of drift, } \mathrm{m} ; \mathrm{r}_{\mathrm{w}}=\text { latent heat of vaporisation, } \mathrm{J} \cdot \mathrm{kg}^{-1} . \\
& \tau \quad=\text { ventilation time, } \mathrm{s} .
\end{aligned}
$$


When $\beta_{d}=0$, the drift wall is totally dry. In most cases, the drift wall would be partially wet, hence, the temperature of the drift wall is:

$$
t_{w}=f \cdot t_{w w}+(1-f) \cdot t_{w d}
$$

where:

$$
\begin{aligned}
& t_{w d}=\text { temperature of dry drift wall, }{ }^{\circ} \mathrm{C} . \\
& t_{w w}=\text { temperature of wet drift wall, }{ }^{\circ} \mathrm{C} .
\end{aligned}
$$

\subsection{Programming the prediction model}

A computer program automates the heat prediction model (Zhou et al. 2002; Zhao et al. 2008; Lowndes et al. 2004). Figure 4 shows the programming flowchart, and in this study, a helpful program was developed using $\mathrm{C}++$ programming language.

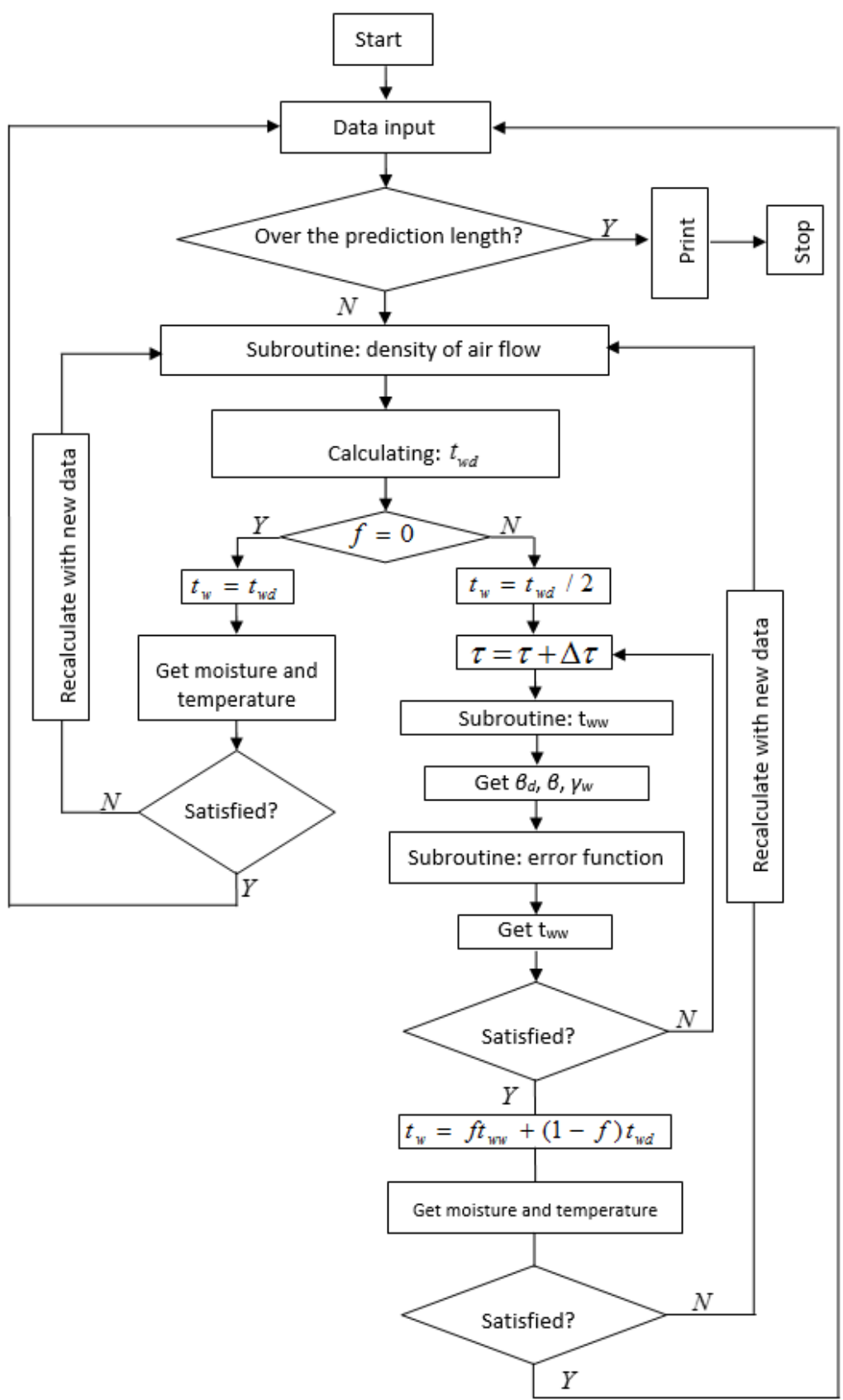

Figure 4 Programming flowchart 


\subsection{Validity check of the prediction model}

A validity check was accomplished by comparing the predicted data with measured dry bulb temperature data from different depths, different drift lengths and moisture data of different depth. In the calculation, the airflow speed is $1.5 \mathrm{~m} / \mathrm{s}$.

Comparison of measured data with predicted data (Figure 5) validated the heat and humidity transfer model of intake air with increasing depth. Hence, the model can be applied at greater depth.

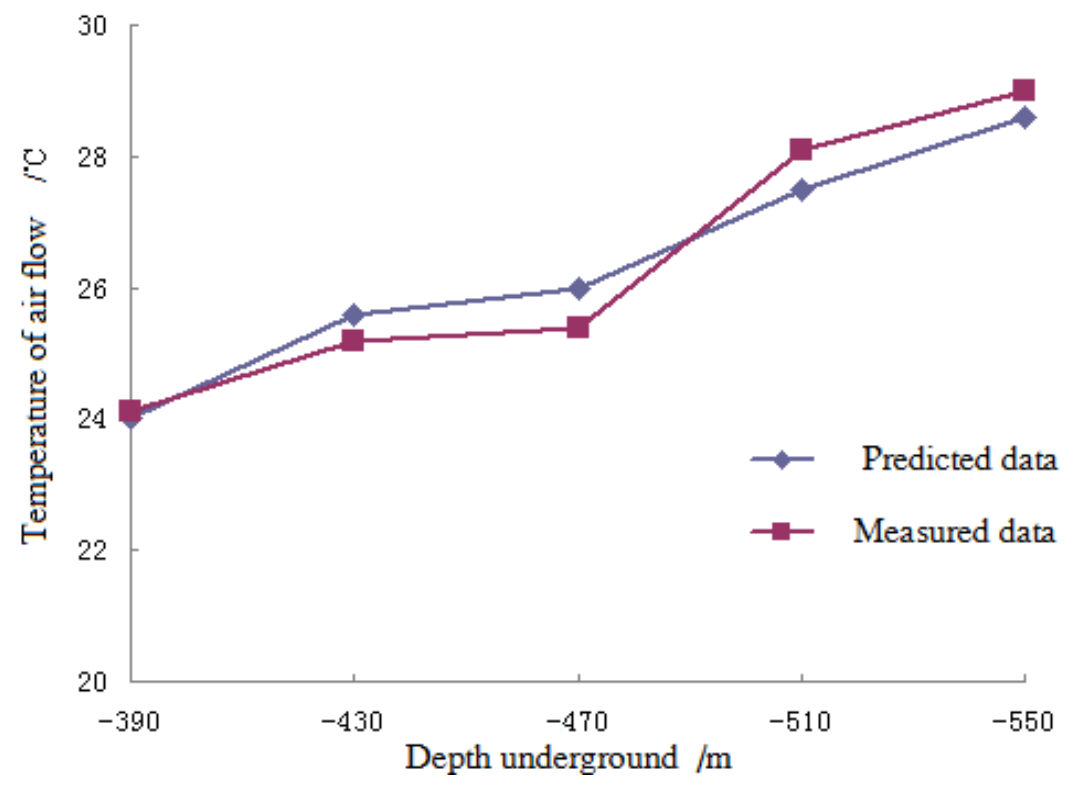

Figure 5 Air flow temperature at different depths

At a certain depth, air flow temperature would be greatly affected by the inner thermodynamic resources within the drift, especially at shallow levels. As there is a bigger temperature difference, there will be prominent heat and moisture transference. Air flow temperature comparison for different drift lengths shows that predicted temperatures model the measured data well (Figure 6).

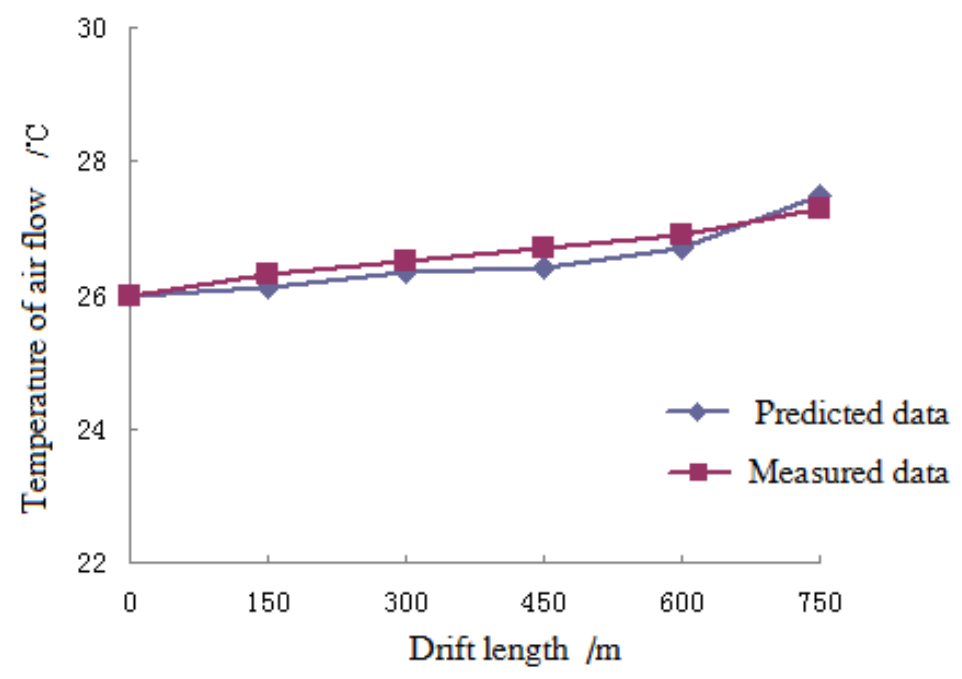

Figure 6 Temperature of air flow in a drift at different length

Figure 7 shows the comparison of predicted and measured relative humidity with changes of elevation in the Jiudian gold mine. The figure exactly reflects the thermodynamic and moisture transferring process. As intake airflow flows down into the mine, heat transfers from the rock to air gradually, and the air temperature rises accordingly; meanwhile, relative moisture decreases initially and then increases. 


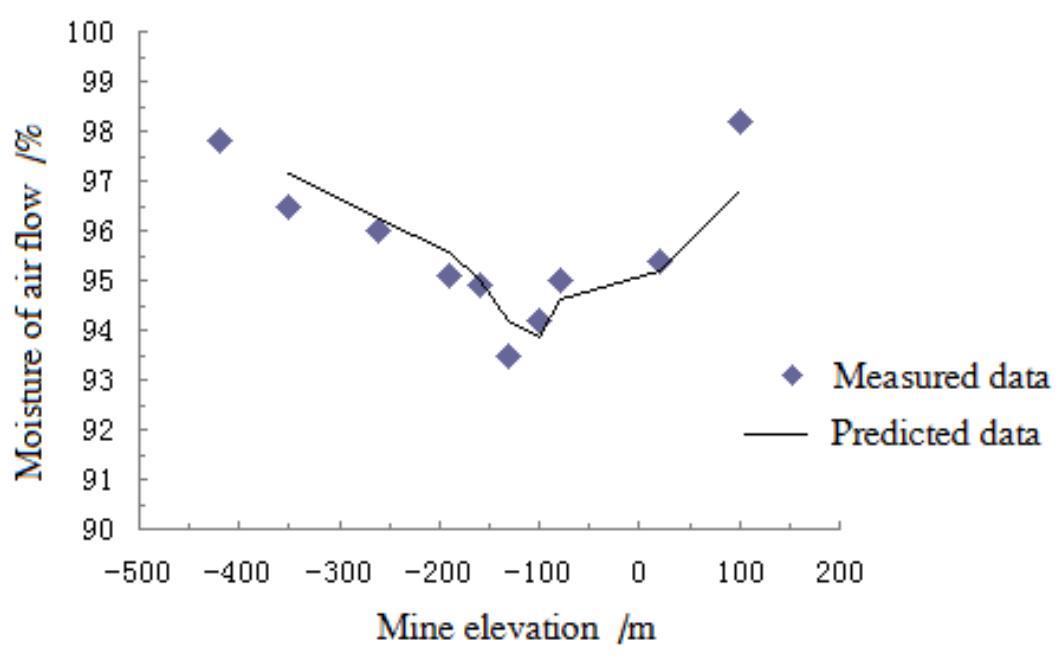

Figure 7 Relative humidity of air flow versus mine elevation

It is apparent from Figures 5 to 7 that the predicted data have a good consistency with the measured data in mine.

\section{$4 \quad$ Concluding remarks}

Underground environment parameters of the Jiudian gold mine have been measured in situ. The highest temperature recorded was $30.8^{\circ} \mathrm{C}$ which exceeds the national standard for underground mining. Based on mass and energy conservation laws, an environment parameter prediction model has been put forward in this paper. By comparing measured data with predicted data, the reliability of the prediction model has been proved. The prediction model can be used in air flow treatment design for underground mines.

To cope with heat load problems in the mine, ventilation network optimisation was accomplished, and intake airflow was adjusted. After these changes, the work face temperature can meet the standard requirements. Further study for the comprehensive utilisation of geothermal energy is being planned.

\section{Acknowledgement}

The authors are grateful for the financial support of the National Nature Science Foundation of China (No. 51204100) and the support of China Scholarship Council (No. 20153012).

\section{References}

Brake, DJ 2002, 'Fan total pressure or fan static pressure: which is correct when solving ventilation problems?', Mine Ventilation Society of South Africa, vol. 55, no. 1, pp. 6-11.

Chen, AG 2004, 'Causes and treatments of heat hazards in underground mine', Chinese Journal of Safety Science, vol. 14, no. 8 , pp. 3-6.

Chen, XZ 1993, 'Drilling hole measurement of rock temperature in the Pingdianshan mining area', Zhongzhou Coal Mining, no. 3, pp. 28-30.

Chow, WK 1995, 'On ventilation design for underground car park', Tunnelling and Underground Space Technology, no. 10, pp. 225-245.

Hu, TY 1994, 'Measurement method of rock original temperature in underground mine', Science \& Technology of Mining Industry, no. 1 , pp. 60-63.

Li, J, Zhang, WY \& Wang, YY 2002, 'Study on skin sensitive difference of human body sections under clothing-multiple analysis of skin surface temperature changes', Journal of Dong Hua University, vol. 28, no. 3, pp. 13-19.

Liu, HG, Wu, C, Wang, WJ \& Chen, SQ 2005, 'Comments on technology progress of lowering temperature in underground mine', Metal Mining, no. 6, pp. 37-41.

Liu, JE, Wang, PZ \& Yao, D 2008, 'Mines high temperature and high humidity environment hazard analysis and treatment measures', Industrial Safety and Environmental Protection, vol. 34, no. 9, pp. 27-28.

Lowndes, IS, Crossle, AJ \& Yang, ZY 2004, 'The ventilation and climate modelling of rapid development tunnel drivages', Tunnelling and Underground Space Technology, no. 19, pp. 139-150. 
Lowndes, IS, Tang, ZY, Jobling, S \& Yates, C 2005, 'A parametric analysis of a tunnel climatic prediction and planning model', Tunnelling and Underground Space Technology, no. 21, pp. 520-532.

Lu, SL, Zhu, N, Feng, GH \& Sun, LJ 2007, 'Experimental research on people's heat endurance in high temperature and humidity environments', Journal of Shenyang Jianzhu University (Natural Science), vol. 23, no. 6, pp. 982-985.

Peng, HY 2014, Effect of individual differences on physiological responses under hot-dry and hot-humid environment (D), Tianjing University, Tianjin.

Standardization Administration of the People's Republic of China 2006, GB16423-2006 Safety regulations for metal and non-metal mines, China Standards Press.

Su, ZG, Dong, WG \& Cheng, WM 2008, 'Study on the comfortableness and evaluation factors of high-temperature underground mine', Safety and Environmental Protection of Mining Industry, vol. 35, no. 3, pp. 72-76.

Tan, HW 2007, 'Heat hazard and its treatment of underground metal deep mine', Gold, vol. 28, no. 2, pp. $20-22$.

Zhang, YL 2012, Comprehensive research on underground heat management and heat utilization of Jiudian gold mine, dissertation, University of Science and Technology Beijing, Beijing.

Zhao, JY, Liu, JP \& Sun, J 2008, 'Numerical simulation of the thermal environment of urban street canyon and a design strategy', Building Simulation, no. 3, pp. 261-269.

Zheng, CB, Zhang, CZ, Xu, B, \& Xu, HB 2009, 'Analysis of formation conditions of terrestrial heat in Jiudian gold mine', Ground Water, vol. 31, no. 5, pp. 124-126.

Zhou, XH, Wang, JR \& Shan, YF 2002, 'Numerical modelling of air flow temperature in drift excavation', Chinese Journal of Safety Science, vol. 12, no. 2, pp. 19-23.

Zuo, JB 2009, Study on prediction model of air flow temperature in heat underground mine, dissertation, Anhui University of Science \& Technology, Huainan. 